\title{
Learning Strategies in Enterprises: empirical findings, implications and perspectives for the immediate future
}

\author{
Ulrik Brandi \& Rosa Lisa Iannone
}

\section{Introduction}

With an empirical study at the enterprise level, we direct our attention to learning strategies, how they may be conceptualised, operationalised and leveraged towards competence development and high-performance. We present a conceptual model of learning strategies, laying the foundation for our empirical research into today's enterprises' learning needs and human resource (HR) commitments.

We begin by introducing the impetus for the current undertaking, arguing that our knowledge of the enactment of learning strategies in enterprises demands further inquiry. Secondly, based on a synthesis of past empirical and theoretical work, we devise a conceptual model that helps us to grasp and interpret empirical data on learning strategies in enterprises. Our model consists of three main dimensions: skills development; learning systems and incentives; and work design and the organisation of work. We then present findings from our empirical research along these dimensions and follow up on each with a discussion of immediate and practical implications for areas of great impact on learning strategies in enterprises.

\section{Framing Workplace Learning between Research and Practice}

For the EU, lifelong learning has long been considered a primary vehicle for adapting and developing competitive capability and economic growth in order to support social cohesion (Aspin \& Chapman, 2000; Elfert, 2015; Holford et al., 2008; Riddell, Ahlgren, \& Weedon, 2009). To that end, governmental bodies have turned to learning strategies to build individual, civic, social and economic knowledge and skills by prioritising investments in competence development and HR, emphasised by the European Community as part of its key messages in the Memorandum on Lifelong Learning (CEC, 2000) and the Lisbon Agreement (CEC, 2001).

The policy discourse - also comprising other transnational governmental bodies such as the OECD and UNESCO - states that lifelong learning is necessary and valuable for individuals, organisations and societies in order to be able to meet the challenges posed by the knowledge economy (Tuijnman \& Boström, 2002). From lifelong learning research, we can perceive a shift in the main focus of continuous education throughout life, from the early 1990 s to a contemporary focus on the term learning as a signifier for learning that takes place beyond the boundaries of formal education in institutional systems or enterprise trainings (Billett, 2010; Felstead et al., 2009; Hager, 2011).

Correspondingly, organisational and workplace learning researchers and practitioners have, for decades, gravitated towards how to manage and understand learning and competence development in the workplace (Argyris \& Schön, 1996; 
Billett, 2004a; Edwards \& Usher, 2001; Eraut, 2007; Hager, 2004). This has led to a more prevalent distinction between formal (including formalised nonformal) and informal learning. In general, formal learning is identified as traditionally organised 'educational' events, whilst informal learning refers to learning that emerges from situated activities and practices, e.g. solving a work-related problem, collaborating and being part of a community of practice (Beckett \& Hager, 2002; Nilsson \& Rubenson, 2014). Workplace and organisational learning research has produced a vibrant body of knowledge on learning at, in and through the workplace (Billett \& Choy, 2013; Easterby-Smith, Crossan, \& Nicolini, 2000; Eraut, 2007; Evans, 2006; Marsick, 1987). Current empirical and theoretical knowledge underscore that workplace learning is multi-facetted and deeply contextualised, e.g. influenced by political and economic systems, industry type, size and profession, forms of organisation and knowledge, work environment and individual knowledge, and experiences in specific work situations (Billett, 2004b; Felstead et al., 2009; Hager, 1998, 2004; Nilsson \& Rubenson, 2014; Tynjälä, 2008).

However, though the value of workplace learning continues to receive careful consideration from researchers and practitioners, actualised through private and governmental initiatives, knowledge on how organisations can strategically arrange and support (rather than customarily 'manage') formal and informal learning in workplaces still largely eludes us (Billett \& Choy, 2013, p. 272; Felstead et al., 2009: 204; Fuller \& Unwin, 2011, p. 21). Hence, our knowledge of how learning strategies are perceived and deployed in today's enterprises and what policymaking can do for the enactment of such strategies call for further empirical and theoretical scrutiny. Practitioners and policymakers are currently tasked with tentatively applying strategies in their search for 'optimal' and 'best fitted' learning designs for their workplaces. As also evidenced in our empirical findings presented below, this provokes an emphasis on formal learning, a concentration on hard skills' development, and outcome-oriented learning, meaning that training is often strongly linked to tangible business goals.

As Fuller and Unwin (2011, p. 21) and Felstead et al. (2009) underline, we see an important challenge to the often-mentioned dominating approach to learning which emphasises the acquisition and transfer of knowledge and hard skills through behavioural and cognitive learning. Greater attention to 'soft' skills and knowledge that are located and created in specific work contexts echoes the need for a balance between Sfard's acclaimed metaphors of learning - acquisition and participation; as 'too great a devotion to one particular metaphor can lead to theoretical distortions and to undesirable practices' (1998, p. 4).

We argue that learning strategies are very closely intermingled with on-thejob needs, connected to the informal arena, and that employees mostly respond to intrinsic motivational enterprise policies and to how work is organised. Overall, this impresses our espousal of a socio-cultural understanding and design of learning strategies, rather than a focus on workplace learning as being primarily a question of access, procurement, control and management of formal educational initiatives. In this respect, we have endeavoured to research more globally on learning that emphasises processes - strategies - rather than control or HR managerial tactics. This stance has also enabled us to link strategic learning 
dimensions to learning approaches that can resolve dynamic learning gaps in our workplaces. Thus, in this article, we examine learning strategies in workplaces so that a useful connection can be made between the vast empirical and theoretical studies that address learning in workplaces, which, nevertheless, inadequately explain how workplace learning becomes transformed into value creation and high-performance. Deeper knowledge on this issue has implications for practice and policy. Specifically, this article focuses on two questions: 1) how can learning strategies used for value creation and high-performance in workplaces be succinctly conceptualised, empirically and theoretically, in a way that embraces the spectrum of formal and informal learning?; and 2) what are the (contemporary and empirically evidenced) main learning needs according to this conceptualisation?

\section{Conceptualising Learning Strategies in Enterprises}

We began our examination of enterprises' learning strategies by synthesising insights from empirical works published between 1990 and 2012 (Brandi et al., 2013; Brandi \& Iannone, 2015), giving particular attention to the association between workplace learning and high-performance work systems. The literature predicates that learning strategies in enterprises encompass policies, practices, processes and outcomes used in the ongoing inclusion and development of competences so as to close employment and socio-economic gaps. These aim to attract and enhance employee and organisational capacity in order to integrate, manage and develop knowledge and skills. Lepak et al. (2005, p. 43) present a concise categorisation of the various HR practices used by enterprises, revealing a broad spectrum that involves transactional strategies (e.g. record keeping, benefits administration) at one end, moving towards traditional (e.g. performance management, training, compensation), and then transformational strategies (e.g. knowledge management, organisational development, strategic planning) at the other.

It is noteworthy that HR strategies from transactional and traditional practices emphasise the cognitive and behavioural aspects of learning, leaning very much towards Sfard's (1998) metaphor of acquisition. HR administration that compensates according to capacity and outcome-specific results, such as through benefits, recruitment and performance management, cultivates learning that reinforces, can be managed and specialises. Transformational strategies begin to open towards a socio-cultural understanding of learning, encouraging learning from Sfard's (ibid.) participation metaphor, with possibilities for what Argyris and Schön (1996) describe as the root of productive learning patterns which have longer-lasting perspectives and results. Overall, Lepak et al.'s (2005) categorisation considers practices that address enterprise and employee needs, as well as learning. This inspired our overall conceptualisation of learning strategies in enterprises; however, rather than using a spectrum to identify and interpret strategies, we began seeing interrelations between them. Thus, our conceptual model is non-linear, emphasising how together - learning strategies support value creation and high-performance.

Contemporary studies in the field of HR management (Becker \& Huselid, 2006; Huselid \& Becker, 1995; Kang, Morris, \& Snell, 2007; Lepak et al., 2005; Prieto Pastor, Santana, \& Sierra, 2010) have attempted to capture the relationship between learning in the workplace, competence development and enterprise 
performance so that best practices and stronger policies can be responsibly used to sustain and strengthen these aspects. From our research, we perceive that HR practices are used strategically to attract and enhance employee competences in order to secure and strengthen enterprise competitiveness and increase enterprise value in varied ways. Delery and Doty $(1996$, p. 802) stress the strategic perspective in the design of HR practices and the desire for researchers to be able to establish the best composition of practices for optimal enterprise performance. They touch upon one of the fundamental issues and challenges for HR management, i.e. how to best arrange and deliver learning strategies in enterprises so that business goals are attained. One of the main results of their study is that HR, though easily overlooked as a driver of business, is unquestionably linked to value creation and performance. In light of this, learning strategies can be viewed as central in HR management's domain. Delery and Doty (ibid., p. 815) further elaborate on the particular characterisations of HR practices in use (focusing on high-performance work systems), resulting in the following index:

1. Internal career opportunities: the existence of clear internal career ladders and staffing systems in an enterprise;

2. Appraisals: the use of performance appraisals focused on output or results in the enterprise;

3. Training and education: the degree and quality of formal and informal training programmes offered to employees;

4. Employment security: the degree to which employees can anticipate to continue in their job over an extended period of time;

5. Employee participation: the degree to which employee input and ideas are allowed and valued by the enterprise;

6. Job descriptions: the extent to which job tasks are clearly defined;

7. Profit-sharing: the degree to which employees receive bonuses based on the enterprise's revenue.

Once again, we see that both of Sfard's (1998) metaphors for learning are highlighted and that the spectrum of transactional, traditional, and transformational HR practices (Lepak et al., 2005) are included as part of strategic and effective enterprise value creation. Other researchers in the field have developed similar indexes to the one above, e.g. Pfeffer (1999, p. 37), arguing for the strategic importance of developing knowledge, skills and competences in optimising performance and establishing HR practices as essential to business success. Overall, we note a strong homogeneity in the field with respect to the delivery options available to deploy HR practices, and strong coherence in the premise that learning is integral to enterprise performance.

Inspired by Delery and Doty (1996), Huselid and Becker (1995), Batt and Colvin (2011), and Prieto Pastor et al. (2010), and based on our review of relevant empirical and theoretical work published between 1990 and 2012, we find that the main HR practices to foster and strengthen high-performance capacity are: training and development, selective hiring, performance appraisal and career management, employment security, compensation and work organisation, and the provision of learning opportunities. We therefore conceptualise learning strategies in the workplace as: 


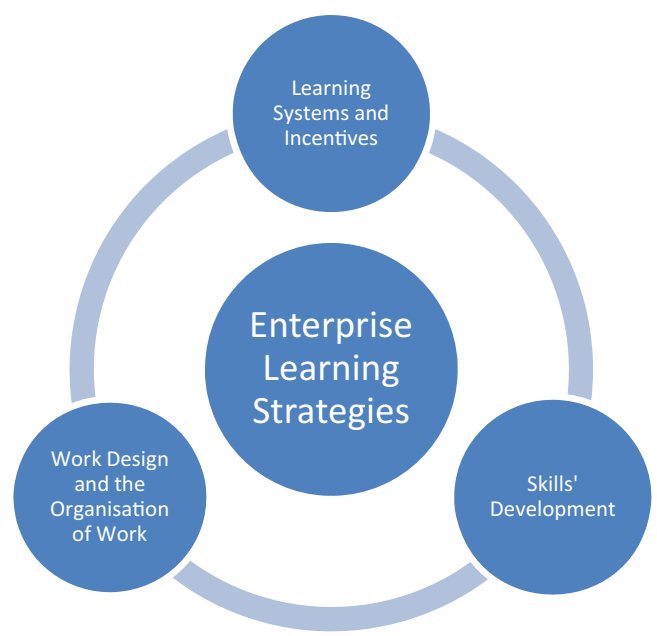

FIGURE 1. Learning strategies in enterprises

The skills development dimension underscores the importance of formal and nonformal learning initiatives in and around the workplace, as well as staffing and career development chances in the enterprise. Combinations of learning strategies within this dimension aim at providing the enterprise with direct means of improving competence thresholds and inducing the workforce as a whole with the capacity of ongoing learning. Focus on the skills development dimension is characterised by an outlook on hard (specific) and soft (non-specific) competences in combination with training and learning activities that are highly sensitive to different types of enterprise needs (e.g. project needs, client needs, employee needs, knowledge gaps, etc.). This connects to the cognitive aspects of learning. Hence, cognitive and action learning approaches (Argyris \& Schön, 1996) can be seen as most effective when considering the learning strategy (Figure 2).

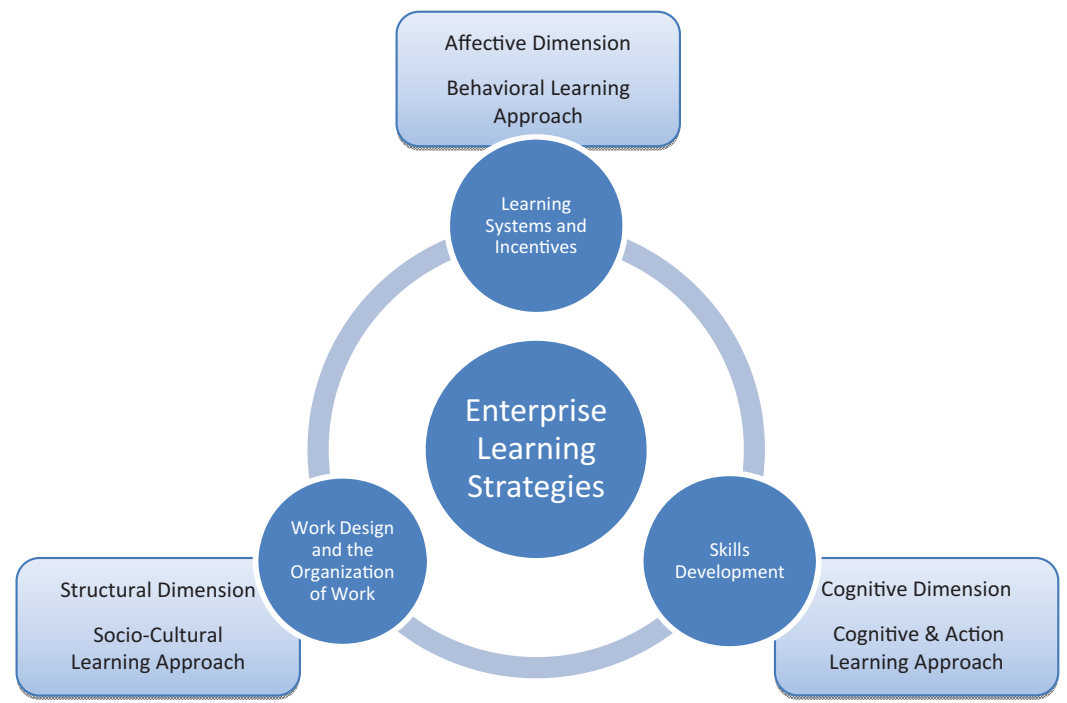

FigURE 2. Learning strategies in enterprises, with learning dimensions and approaches 
The second dimension, incentive structures, relates to generating, managing and facilitating a learning system that is conducive to producing and sustaining the high commitment, security and motivation of the workforce with different types of rewards, wage levels and appraisal inducements. Prieto Pastor et al. (2010, p. 2456) describe this dimension as oriented towards building trust in and across the enterprise, thus indirectly facilitating a productive platform for creating new ideas and sharing knowledge. This addresses the affective aspects (Kang et al., 2007) of learning, for which learning strategies that draw from behavioural learning approaches are most effective.

The third dimension, work design and the organisation of work, addresses how enterprises organise work in order to create an all-encompassing foundation for the creation of learning and competence development. Batt and Colvin stress that the main aim of work design in high-performance work systems is to 'provide opportunities for individual discretion and ongoing learning through collaboration with other employees' (2011, p. 588). Creating a coherent enterprise that draws on a sociocultural set-up where continuous learning is a sine qua non through participation in selfdirected teams and problem-solving tasks is mandatory according to the vast majority of research and empirical findings. Concerning the relation to well-functioning work design, studies underscore that employees should be given a high degree of independence, decision-making and influence on how work processes are organised. In order to create and sustain learning and innovation, low risk-aversion and embracing challenges are seen as significant factors, together with a flexible and teambased work organisation. This dimension relates to the structural dimension of learning (Kang et al., 2007), which benefits from socio-cultural learning strategies (Brown \& Duguid, 1991; Wenger, 2000).

To come back to our first question, How can learning strategies employed towards value creation and high-performance in workplaces be succinctly conceptualised, empirically and theoretically, in a way that embraces the spectrum of formal and informal learning?, our analysis of past empirical and theoretical studies leads us to understand more precisely what learning strategies in enterprises are, whilst embracing a wide spectrum of available methods and actions in each of the dimensions, Sfard's (1998) learning metaphors, formal and informal learning, and the behavioural, cognitive and socio-cultural approaches to learning, contextualised by an enterprise's value creation goals.

\section{Empirical Findings for Learning Strategies in Enterprises}

Our empirical study focused on workplaces as learning sites and how the conceptualised learning strategies (see Figure 1) were being actualised in today's enterprises, addressing specific learning needs and HR commitments. It was designed according to abductive reasoning, which is characterised by a transaction between data and theory as a way to account for empirical findings (Bertilsson, 2004; Locke, Golden-Biddle, \& Feldman, 2008; Timmermans \& Tavory, 2012). The empirical findings draw on research we undertook between 2013 and 2015, including semi-structured interviews with selected management, HR and union representatives and questionnaire responses from a total of 194 enterprises (staff and management from $31 \mathrm{EU}$ and 163 EU-competitors) across 53 industries. Our interview guide and questionnaire were structured along the learning strategy dimensions we discerned (see Figure 1). Responses were analysed following a thematic approach 
(Braun \& Clarke, 2006) and synthesised into enterprise mini-cases per participating enterprise. The findings we present below address our second question: What are the (contemporary and empirically evidenced) main learning needs according to our conceptualisation of learning strategies in enterprises?

\section{Skills Development}

We noted a strong emphasis on the importance of soft skills, particularly in regards to interrelationships, and their contribution to productive patterns of work (Argyris \& Schön, 1996). Respondents noted that both hard and soft skills were desirable in the workplace, with notable attention to soft, or transversal skills (see Figure 3). Irrespective of the technical complexity of our participants' work and the rarity or scarcity of hard skills in the various professions (e.g. in engineering, medical, accounting and aerospace enterprises), skills such as 'communication', 'creativity', 'customer service', 'interpersonal relations' and 'teamwork' came out as most valued. 'Knowledge' and cognitive skills were also highlighted as important, though it is the ability to apply and the ability to communicate knowledge that contribute to the valuation of knowledge as a skill.

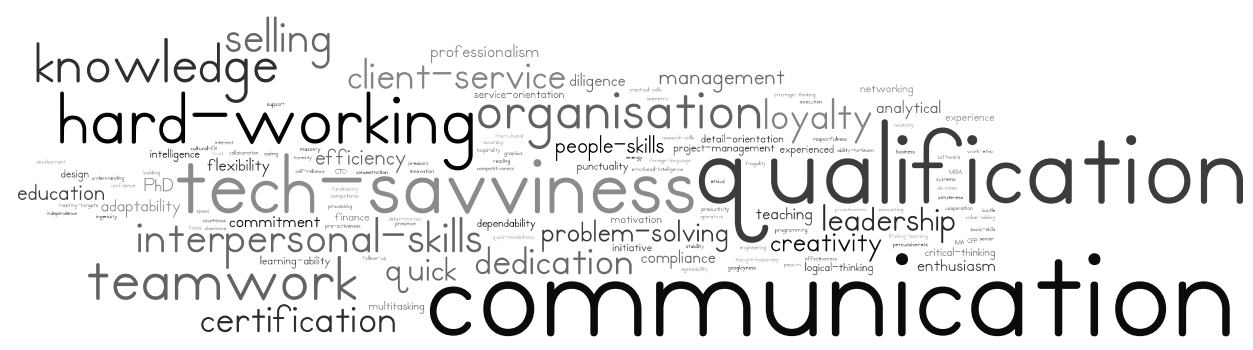

Figure 3. Most valued employee skills

Despite this, HR remains ill-informed and ill-equipped to take stock of, or measure levels of soft skills in workplaces and their gaps for example. Thus, investment in soft skills is something that has more and more become an individual's responsibility. All our interviewees stressed that measurements/calculations were difficult, if not impossible, with respect to learning and development, particularly concerning soft skills. As a result, enterprises indirectly measure gaps and the benefits of learning in these areas by counting the number of training hours per year and clients, collecting experiential feedback from employees, staff peer-evaluations, self-evaluations, and other general performance appraisal information. Interviewees also revealed that there is a gap in the demand versus provision of soft skills' development:

Interviewer: If you think of last year, did you have more, or less, training than asked for?

Interviewee: Technical issues, we covered it all. [...] More general issues like language or project management we had significantly more people wanting courses than we offered (Director of Labour Relations, Enterprise DE250C29SSI7: pp. 1-2).

As suggested by the quote above, provided by a respondent in a large enterprise of the motor vehicle manufacturing industry, without tools that clearly define the value added of investing in soft skills' development, budgets will be allocated to hard skills' training. On this basis, there is a need for measurement tools in terms of 
soft skills and impact on workplaces so that investments and commitments in soft skills' development may become a more strategically understood practice.

\section{Learning Systems and Incentives}

We also noted from participants that there was a clear pattern of intrinsic rewards being more important and valued than extrinsic ones (Figure 4):

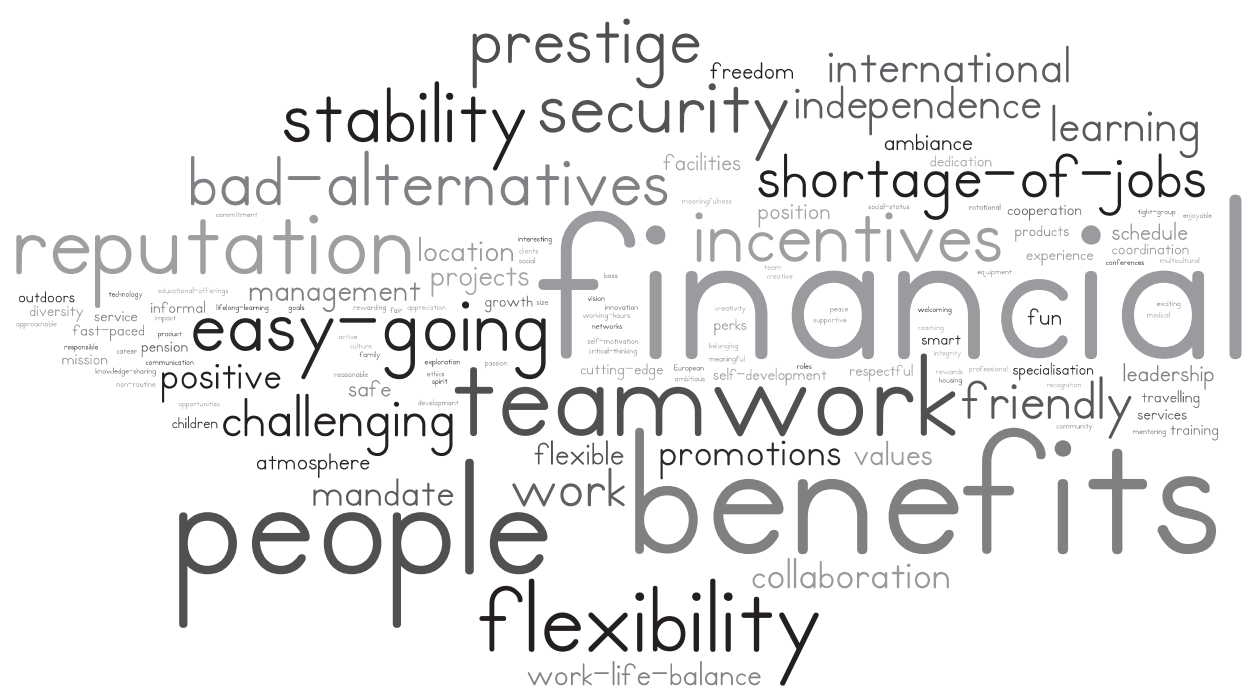

FIGURE 4. Appeal of the work environment, acquiring and keeping staff

A positive atmosphere, providing access to state-of-the art tools and software, strengthening employee cohesion and the like are all enabling aspects of performance in the workplace and value creation. These motivational factors act to attract staff and ensure retention. To begin, financial compensation was mentioned the most, together with benefit packages, which include medical, retirement, vacation and other traditional compensation items. This satisfies the extrinsic motivational factors of having a job and earning enough to secure a livelihood and future. Following this, we have 'people' and 'teamwork', as well as 'reputation', 'flexibility' and 'stability' - all intrinsic motivators. In fact, there are mentions of many more intrinsic aspects of workplace environment than extrinsic aspects, as illustrated in Figure 4. Altogether, our participants' responses reinforce Herzberg's (2003) thesis that there are elements that lead to satisfaction in the workplace and others that directly contribute to dissatisfaction. People first need to satisfy the basics of earning for the present and some for the future (e.g. retirement); but there is much more that contributes to a sense of satisfaction. Several of our interview narratives tell of these positive motivators, strengthening the premise that intrinsic motivators, addressing higher-order needs, result in happiness in the workplace and benefits for the enterprise. This was the case at one enterprise which is a large $(250+$ employees) and newly established enterprise in the IT (information Technology) and computer services industry: 'For us, we think that training and giving options to all is a huge way of making people happy here and making people stay with the company. So this is the goal' (Senior Manager Research and Development, Enterprise 
DE250J62SSI10: pp. 4-5). This is an example of how a fast-growing, highly technical enterprise uses training and development as a concrete reward that is closely tied to the business strategy of strengthening the impetus for employees to stay with the company.

To bridge the needs and provisions of learning in workplaces, we found that the most successful types of learning reported by our participants related to jobspecific, learner-centred, in-house, classroom, group and one-to-one initiatives. Certificates and policy-mandated trainings were also noted as popular and effective, particularly since they directly target the highly practical requirements of work. This highlights a focus on the cognitive and behavioural dimensions of learning as current learning strategies for enterprises. Noteworthy are 'soft-skills' being mentioned as a successful type of learning outcome, emphasising again their importance in workplaces and HR commitment. Respondents reported informal, workshoptype, seminars, short courses and online/digital contexts as befitting to continuous learning. In line with the premise that learning must be continually renewed, we can discern that the most effective learning occurs on-demand.

\section{Work Design}

Disjuncture, as we know from adult and experiential learning theory (Dewey, 1938/ 1988; Jarvis, 1987), prefaces learning and growth; it presents opportunities for learning in that we face an unexpected change which demands some thought from us or a team. In line with this, work design that incorporates collaboration, teambased work, special assignments and job-rotations plays an important role in ongoing learning in the workplace, whilst also serving employees' intrinsic needs. Stress and conflicts, however, present unhealthy, unproductive, unconstructive challenges that may severely impinge on employee happiness and enterprise goals. The most common workplace conflicts our respondents reported, relate to soft skills' gaps, depicted in Figure 5. They highlighted 'stress' as the most onerous, linked to burn-outs, followed by communication problems, conflicts with clients, workload difficulties and conflicts between management and staff.

These point to interpersonal difficulties and other challenges that deal with the skills' development dimension. For example, stress and burn-outs could be alleviated by either better time-management skills, or managed expectations from the enterprise. As we begin to contextualise some of the challenges and conflicts that employees reported, we see that pressures from industry, clients, resources, etc. all influence communication patterns, work organisation in general and employee stress sources at work. Of course, in high-performance work systems, priority to responsiveness in conflicts and challenges are characteristic. And, from organisational learning theory, we know that some solutions are in the detection and correction of problems, whilst others require a deeper examination of and change to inherent values in the organisation of work (Argyris \& Schön, 1996).

Top-down and bottom-up decision-making power could be legacies from sociohistorical conditions. In enterprises whose operations rely mostly upon labourintensive work that is routine, we have an example that tells how to leverage employee agency, despite the organisation of work that reduces independence and decision-making power. The head of a Slovakian enterprise of around 120 employees, operating in the manufacturing of porcelain and ceramic products explained: 


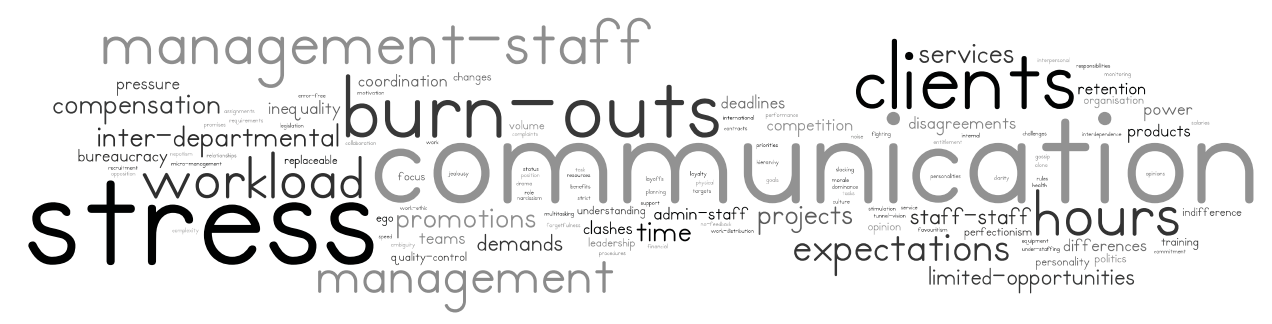

Figure 5. Most common conflicts size

I personally seek to make them [employees] understand the underlying processes, and to act proactively, to anticipate problems and avoid larger damages. [...] We are world-wide leaders in enameling technology for steel bathtubs and shower trays. That gives us major strength in terms of quality, aesthetic parameters and the production costs of the products. [...] For individual employees, crucial is that they have to understand and believe in their own importance, of their own position for the company outcome (Owner and CEO, Enterprise SK11C23SSI8: p. 2).

From the empirical data we gathered in our interviews and questionnaire responses, the pattern of decision-making power over work organisation depicts about half who have personal influence over their work, decreasing as enterprise size increases:

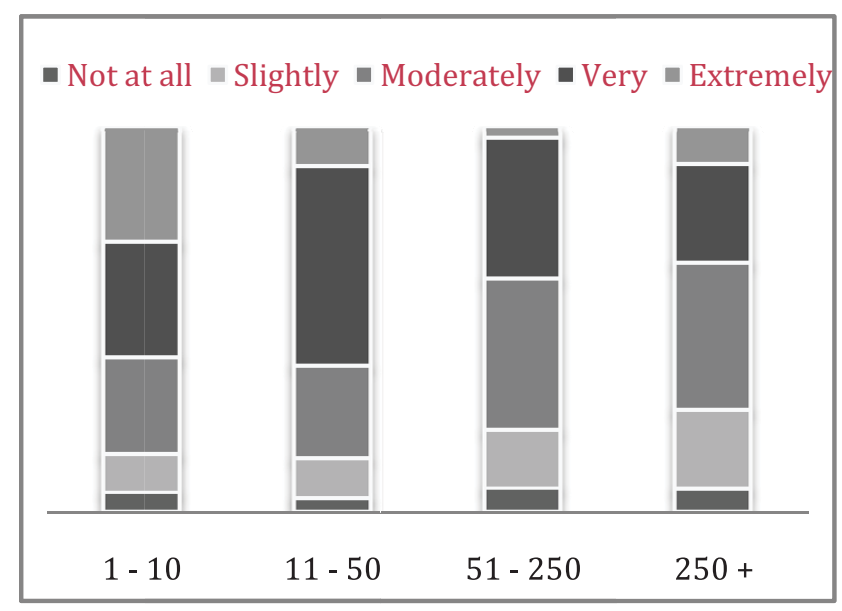

FIGURE 6. Employees having independence, decision-making power and influence over their work design, per enterprise

Individual, as well as collective agency also appear as the most desired aspects of a workplace, as noted in Figure 4, including 'freedom', 'independence', 'flexibility', 'teamwork', 'collaboration' and 'people'. Agency can become overwhelmed by hierarchy, bureaucracy and status distinction, which are more pervasive in larger (250+ employees) enterprises. The administrative distinction of an HR-area also tends to lead to a rather top-down organisation of work and this may impinge on enterprise flexibility, employee autonomy and agency, as well as learning and adaptation processes. As expressed by several of our interviewees and our synthesis of past 
empirical studies, these aspects pose challenges to ongoing training and development, particularly with respect to informal and non-formal workplace learning. However, for traditional and transaction HR-practice deployment, such as the administrative management of personnel (e.g. leave, benefits, contracts, etc.), coordinated and transparent HR operations function as facilitators. Nevertheless, and as we have seen from our empirical narratives, hierarchy, bureaucracy and status distinction encroach on feelings of belonging, 'a sense of family' (Senior Manager Research and Development, Enterprise DE250J62SSI10: p. 5) and may also stall performance: 'I think, our general management isn't often in the house, and so you have to wait until they are there to talk about problems you've had for three weeks...' (Loyal Employee of more than a decade of service, Enterprise Anonymous I: p. 8). Also, hierarchy and bureaucracy are highlighted by our respondents as barriers to the most successful types of learning: on-demand, responsive learning to work-related needs, chiefly guided by job-specificity (emphasising informal learning).

\section{Implications and Future Actions for Learning Strategies in Enterprises}

Based on the above, we have new insights on learning needs and commitments in enterprises, which learning strategies and HR can address. Although certain systems give necessary structure and stability to learning, we found that the most effective learning strategies in enterprises were informal initiatives that create modes of learning at work, also influenced by new learning technologies. At the same time, the responsibility for competence development still largely rests on the justification of HR and organisational investment, as well as the impetus of individual and workgroups to be proactive. Our view is that there is ample opportunity for public policy and practice to play a greater role in designing and deploying learning strategies in enterprises around the three learning dimensions of: (hard and soft) skills' development; learning systems and incentives; and work design and the organisation of work.

Firstly, our informants' knowledge of external support for competence development is deficient; there is substantial room for fostering more awareness of, for example, the availability of public funds and other government-sponsored activities that provide opportunities for employees to learn. Of all of our participants, only a handful were aware of the availability of EU-funds and grants. In addition, this blind spot demonstrates that network channels, particularly between policy and practitioners, need to be strengthened. An example of how helpful funding and networks can be for employees is captured in the following narrative from Enterprise ES51QSSI2 in the human health and social work industry in Spain:

Interviewee: When going through the EFQM [European Foundation for Quality Management, www.efqm.org]. process, one of the things that we identified was the need to improve internal communication. To this end, we set up an IT system covering all premises. The implementation of this system was very costly and took a lot of time. In this context, IT training for all staff has been fundamental. The training is for enabling everyone to use our new management software and has been very successful. We have conceived of this training to progress gradually, with very little things to be learned each time. [Because...] We have employees who are 40-50 years old and have 
never completed upper-secondary education or professional training, [...some] personnel had never used a computer before this training initiative! [...] Last year, we contracted a company for doing the management of this [particular financial, government] credit [...]. This year we have decided to use the credit for training in EFQM (Director, Enterprise ES51QSSI2: pp. 4-5).

This enterprise, registered as a not-for-profit charity, is located in a fairly remote part of Spain, which as our four interviewees explained, poses some challenges with respect to staffing and access to skill development opportunities. Yet by leveraging network channels championed by the Director, creative use of social funding sources enabled up-skilling and continual workplace learning. The enterprise successfully achieved ISO certification as well as a certificate of excellence in quality management through the EFQM and introduced new technology, which, as our interviewees emphasised, strengthened competence, confidence, and even local pride.

Secondly, public policy can lend greater support to and recognition of learning that occurs on-the-job and on-demand, as our results highlight that these are the most efficient, relevant and effective learning strategies that can be prompted by emergent needs.

Interviewer: Okay, so [...] you are using these blogs and these online networks then to get answers if you have questions?

Interviewee: Yeah [...]. That's right, but it's an incremental process, it's not like 'you have a session for two days', like a guerrilla camp or something [...]. It's more that it's 'learning by doing'. [...] So, if you have a problem, you have to look at how you can solve it and afterwards, maybe you can select good solutions for it. You have to look for it yourself of course. But it's not. . formal. [...] I think the main source [for learning] is the Internet right now (Project Manager of Software Development, Enterprise DE51M69SSI3: pp. 6-8).

This example, which is representative of today's configuration of skills' development learning strategies, reinforces the premise that learning in the workplace is prompted by individuals in response to immediate and work-/task-related needs and that cognitive learning has evolved into a more social and community sphere through online networks, social learning technologies and the like. Having access to knowledge in and beyond an enterprise (e.g. knowledge repositories, networks, etc.) and to relevant communities of practice (Wenger, 2000) bolsters connectivism (Griffiths \& Guile, 2003; Kop \& Hill, 2008; Siemens, 2005) and also emphasises individuals' skills to collaborate and know where to find solutions - quickly - rather than know the solutions first-hand. Being resourceful and problem-solving ondemand outranks knowing vast amounts of information, particularly since information is in a continual cycle of renewal and update.

Thirdly, we discerned an important knowledge gap in terms of 'optimal' systematic arrangements that promote coherence between structured HR practices and ad-hoc arrangements in learning strategies. New knowledge would enable us to better leverage learning strategies according to available resources and determine a sensible balance between industry standards, globalised business demands and individual skills development. Enterprises would benefit from strategic follow-ups with project and work demands, as well as employee requests, and at the same time, they could plan for flexible training and development offerings that address 
multi-stakeholder needs. And, as our data demonstrate, systematic approaches to learning strategies do not necessarily require top-down planning, even in large enterprises.

Fourthly, our empirical research reveals a scarcity between the valuation of soft skills and investment in soft skills, and that there is also a gap between the demand for soft skills' training and provisions. As such, policy can play a strong role in closing these gaps by focusing social funds and non-financial activities on soft skills' development in workplaces. Also, research on the economic value of soft skills in workplaces would empower decision-makers in enterprises who currently struggle with calculations of return on investment in soft skills' training (Andrews \& Higson, 2008; Bartel, 2000). Our findings reveal that enterprises recognise an existing connection between soft skills and business value creation, but they are still largely illequipped to measure and explain how the connection can be leveraged: 'There is though little evidence that we have good and effective systems and process for assessing soft skill' (Gibb, 2014, p. 468); there is much more than cognitive ability '...valued in the labour market' (Heckman \& Kautz, 2012, p. 451). Specific research on the valuation (measurement) of soft skills' training and development in cross-cultural and cross-industry contexts, drawing on short-term and long-term, quantitative and qualitative data would shed light on this largely intangible connection. Governments can lead the way towards innovative evaluation tools that enterprises can co-create and use in the future learning strategies they adopt.

Fifthly, we see an immediate need to address workplace stress and conflicts and how to counter their effects. Despite important research evidencing an inverse relationship between stress and conflicts and employee wellbeing and performance (Ryan \& Deci, 2000), our respondents, together with data from the European Company Survey from 2009 and 2013, evidence that enterprises still remain ill-equipped or uninformed as to the appropriate strategies that can minimise or counter negative retrogressions and stagnation. Research findings might not be linked enough to workplace practices, practitioners may be under-resourced, or worse, there may not be a strong enough business case made to justify investments in addressing these issues. Our participants reported burn-outs, communication, employee relations and relations between management and staff as their main struggles. Tracing these, understanding them and then finding examples of how to overcome such challenges will directly contribute to a happier, healthier and more productive workforce.

\section{Conclusion}

We have asked how learning strategies used for value creation and highperformance in enterprises could be theoretically devised in a way that would embrace the spectrum of formal and informal learning, HR practices, as well as the acquisition and participation strategies to learning. Based on our synthesis of relevant empirical and theoretical publications (1990-2012), we note that learning strategies in enterprises can be organised into three main dimensions in a model that connects learning strategies to learning dimensions and approaches (Figure 2). Learning systems and incentives connect to the affective dimension of learning, which behavioural learning addresses effectively. Skills' development strategies chiefly address the cognitive dimension of learning to which cognitive and action learning principles can be applied. And, work design and the organisation of work attend to the structural dimension of learning and socio-cultural approaches. 
Based on our conceptual understanding, we empirically explored the learning strategies of today's enterprises, searching for the most pressing needs and commitments. Regarding skills' development, results show that the most valued employee skills are soft skills. Yet for the most part, there is a focus on the development of hard skills that explicitly and directly contribute to new business formation and financial bottom-lines. We found that it was primarily the individual's role to prompt learning in the workplace and that HR remains challenged on how to evaluate soft skills' levels and gaps.

On learning systems and incentives, findings indicate that enterprises strive for a balance between the use of systematic and ad-hoc arrangements, yet still lack the knowledge on how to proceed. We also found that the implementation of incentives that respond to intrinsic needs, such as offering interesting and challenging work, being flexible and fostering a sense of belonging and ownership, were essential learning strategies for high-performance work systems.

Work design and the organisation of work also directly contribute to overall enterprise high-performance and value creation. The systematisation of certain aspects of HR helps, however, hierarchy and employee status distinction hinder learning processes and performance optimisation. Workplace conflicts and challenges emerged as highly influential for learning in enterprises, and ultimately, value creation and performance - stress and burn-outs being the most pervasive and in need of immediate attention.

Our theoretical and empirical results prompt insights that call for policy and enterprise practice to enhance mutual collaboration and knowledge sharing at a multi-stakeholder level. It is clear that the design and deployment of learning strategies in workplaces are key to bolstering lifelong learning, so that organisations and societies can become more agile in responding to the challenges posed by today's knowledge economy.

Ulrik Brandi, Aarhus University, Danish School of Education, Tuborgvej 164, 2400 Copenhagen, Denmark, brandi@edu.au.dk

Rosa Lisa Iannone, Aarhus University, Danish School of Education, Tuborgvej 164, 2400 Copenhagen, Denmark, Email: rli@edu.au.dk

\section{Acknowledgement}

This article is based on data from the Lifelong Learning, Innovation Growth \& Human Capital Tracks in Europe (LLLight'in'Europe) research project. LLLight'in'Europe received funding from the EU's Seventh Framework Programme for research, technological development and demonstration under grant agreement no. 290683. We would like to thank all the research project's members for their inspirational collaboration throughout. A special thank you goes to Richard Desjardins whose comments and questions were very constructive and helped to shape this article.

\section{REFERENCES}

ANDREws, J., \& Higson, H. (2008) Graduate employability, 'soft skills' versus 'hard' business knowledge: a European study, Higher Education in Europe, 33, pp. 411-422. 
ARGYRIS, C., \& SCHÖN, D. (1996) Organizational Learning II: theory, method, and practice (Reading, Massachusetts, Addison Wesley).

BARTEL, A. P. (2000) Measuring the employer's return on investment in training: evidence from the literature, Industrial Relations, 39, pp. 502-524.

BATT, R. \& Colvin, A. J. S. (2011) An employment systems approach to turnover: human resources practices, quits, dismissals, and performance, Academy of Management fournal, 54, pp. 695-717.

BeCKER, B. E., \& Huselid, M. A. (2006) Strategic human resource management: where do we go from here?, foumal of Management, 6, pp. 898-925.

Beckett, D., \& HAger, P. (2002) Life, Work and Learning: Practice in postmodernity (London, Routledge).

Bertilsson, T. M. (2004) The elementary forms of pragmatism: on different types of abduction, European Fournal of Social Theory, 7, pp. 371-389.

BilletT, S. (2004a) Co-participation at work: learning through work and throughout, Studies in the Education of Adults, 36, pp. 190-205.

BILlETT, S. (2004b) Workplace participatory practices: conceptualising workplaces as learning environments, The Fournal of Workplace Learning, 16, pp. $312-324$.

BilletT, S. (2010) Lifelong learning and self: work, subjectivity and learning, Studies in Continuing Education, 32, pp. 1-16.

BilletT, S., \& CHOY, S. (2013) Learning through work: emerging perspectives and new challenges, fournal of Workplace Learning, 25, pp. 264-276.

Brandi, U., Elkjaer, B., Holford, J., IANnone, R. L., Mckenzie, L., \& Mossfeldt, N. (2013) Conceptual model and questionnaire (pp. 61). Report: LLLight'in'Europe: Lifelong learning, innovation, growth and human capital, tracks in Europe.

BRANDI, U., \& IANNONE, R. L. (2015) Effective lifelong learning strategies and value creation at the enterprise level (pp. 95). Report: LLLight'in'Europe: Lifelong learning, innovation, growth and human capital, tracks in Europe.

Braun, V., \& Clarke, V. (2006) Using thematic analysis in psychology, Qualitative Research in Psychology, 3, pp. 77-101.

BRown, J. S., \& DUGUID, P. (1991) Organizational learning and communitiesof-practice: toward a unified view of working, learning, and innovation, Organization Science, 2, pp. 40-57.

CEC, C. o. t. E. C. (2000) Commission Staff Working Paper: a memorandum on lifelong learning (Brussels, European Commission).

CEC, C. o. t. E. C. (2001) Communication from the Commission: making a European area of lifelong learning a reality (Brussels, European Commission).

DELERY, J. E., \& DoTY, D. H. (1996) Modes of theorizing in strategic human resource management: tests of universalistic, contingency, and configurational performance predictions, Academy of Management fournal, 39, pp. 802-835.

DEwey, J. (1938/1988) Experience and education, in: J. A. Boydston (Ed) Later Works 13 (pp. 1-62) (Carbondale and Edwardsville, Southern Illinois University Press).

Easterby-Smith, M., Crossan, M. M., \& Nicolini, D. (2000) Organizational learning: debates past, present and future, fournal of Management Studies, 37, pp. 783-796.

EDWARDS, R., \& USHER, R. (2001) Lifelong learning: a postmodern condition of education?, Adult Education Quarterly, 51, pp. 273-287. 
ERAUT, M. (2007) Learning from other people in the workplace, Oxford Review of Education, 33, pp. 403-422.

Evans, K. (2006) Improving Workplace Learning (New York, Routledge).

Felstead, A., Fuller, A., JEWsON, N., \& UNWIN, L. (2009) Improving Working as Learning (Routledge).

FULLER, A., \& UNWIN, L. (2011) Workplace learning and the organization, in: M. Malloch, L. Cairns, K. Evans \& B. N O'Connor (Eds) The SAGE Handbook of Workplace Learning, pp. 46-59

GIBB, S. (2014) Soft skills assessment: theory development and the research agenda, International fournal of Lifelong Education, 33, pp. 455-471.

GriffiTHS, T., \& GuILE, D. (2003) A connective model of learning: the implications for work process knowledge, European Educational Research fournal, 2, pp. 56-73.

HAGER, P. (1998) Understanding Workplace Learning: General Perspectives (Leabrook, NCVER).

HAGER, P. (2004) Conceptions of learning and understanding learning at work, Studies in Continuing Education, 26, pp. 3-17.

HAGER, P. (2011) Theories of workplace learning, in: M. MALloch, L. CAIRns, K. Evans \& B. N O'CONNOR (Eds) The SAGE Handbook of Workplace Learning (pp. 17-31) (London, SAGE Publications).

Heckman, J. J., \& KaUtZ, T. (2012) Hard evidence on soft skills, Labour Economics, 19, pp. 451-464.

HerzberG, F. (2003) One more time: how do you motivate employees?, Harvard Business Review, 81, pp. 87-96.

Huselid, M. A., \& BECKER, B. E. (1995) The impact of human resource management practices on turnover, productivity, and corporate financial performance, Academy of Management Fournal, 38, pp. 635-672.

JARvis, P. (1987) Adult Learning in the Social Context (London, Croom Helm).

KanG, S. C., Morris, S. S., \& SNell, S. A. (2007) Relational archetypes, organizational learning, and value creation: extending the human resource architecture, Academy of Management Review, 32, pp. 236-256.

KoP, R., \& HiLL, A. (2008) Connectivism: learning theory of the future or vestige of the past?, The International Review of Research in Open and Distributed Learning, 9.

LEPAK, D. P., BARTOL, K. M., \& ERHARDT, N. L. (2005) A contingency framework for the delivery of HR practices, Human Resource Management Review, 15, pp. 139-159.

Locke, K., Golden-Biddle, K., \& Feldman, M. S. (2008) Perspectivemaking doubt generative: rethinking the role of doubt in the research process, Organization Science, 19, pp. 907-918.

MARSICK, V. J. (1987) Learning in the Workplace (London, Croom Helm).

Nilsson, S., \& RubEnson, K. (2014) On the determinants of employmentrelated organised education and informal learning, Studies in Continuing Education, 36, pp. 304-321.

Pfeffer, J., \& VeIGA, J. F. (1999) Putting people first for organizational success, The Academy of Management Executive, 13, pp. 37-48.

Prieto Pastor, I. M., Santana, M. P. P., \& Sierra, C. M. (2010) Managing knowledge through human resource practices: empirical examination on the Spanish automotive industry, International fournal of Human Resource Management, 21, pp. 2452-2467. 
RYAN, R. M., \& DECI, E. L. (2000) Self-determination theory and the facilitation of intrinsic motivation, social development, and well-being, American Psychologist, 55, p. 68.

SFARD, A. (1998) On two metaphors for learning and the dangers of choosing just one, Educational Researcher, 27, pp. 4-13.

SiEMENS, G. (2005) Connectivism: a learning theory for a digital age, International Fournal of Instructional Technology and Distance Learning, 2, pp. 3-10.

Timmermans, S., \& TAVORY, I. (2012) Theory construction in qualitative research: From grounded theory to abductive analysis, Sociological Theory, 30, pp. 167-186.

Tuijnman, A., \& Boström, A. K. (2002) Changing notions of lifelong education and lifelong learning, International Review of Education, 48, pp. 93-110.

Tynjälä, P. (2008) Perspectives into learning at the workplace, Educational Research Review, 3, pp. 130-154.

WENGER, E. (2000) Communities of practice and social learning systems, Organization, 7, pp. 225-246. 